\title{
A New Kind of Ancestor:
Ardipithecus Unveiled
}

The oldest known hominin skeleton reveals the body plan of our very early ancestors and the upright origins of humankind

Every day, scientists add new pages to the story of human evolution by deciphering clues to our past in everything from the DNA in our genes to the bones and artifacts of thousands of our ancestors. But perhaps once each generation, a spectacular fossil reveals a whole chapter of our prehistory all at once. In 1974, it was the famous 3.2-million-year-old skeleton "Lucy," who proved in one stroke that our ancestors walked upright before they evolved big brains.

Ever since Lucy's discovery, researchers have wondered what came before her. Did the earliest members of the human family walk upright like Lucy or on their knuckles like chimpanzees and gorillas? Did they swing through the trees or venture into open grasslands? Researchers have had only partial, fleeting glimpses of Lucy's own ancestors - the earliest hominins, members of the group that includes humans and our ancestors (and are sometimes called hominids). Now, in a special section beginning on page 60 and online, a multidisciplinary international team presents the oldest known skeleton of a potential human ancestor, 4.4-million-year-old Ardipithecus ramidus from Aramis, Ethiopia.

This remarkably rare skeleton is not the oldest putative hominin, but it is

by far the most complete of the earliest specimens. It includes most of the skull and teeth, as well as the pelvis, hands, and feet—parts that the authors say reveal an "intermediate" form of upright walking, consid-
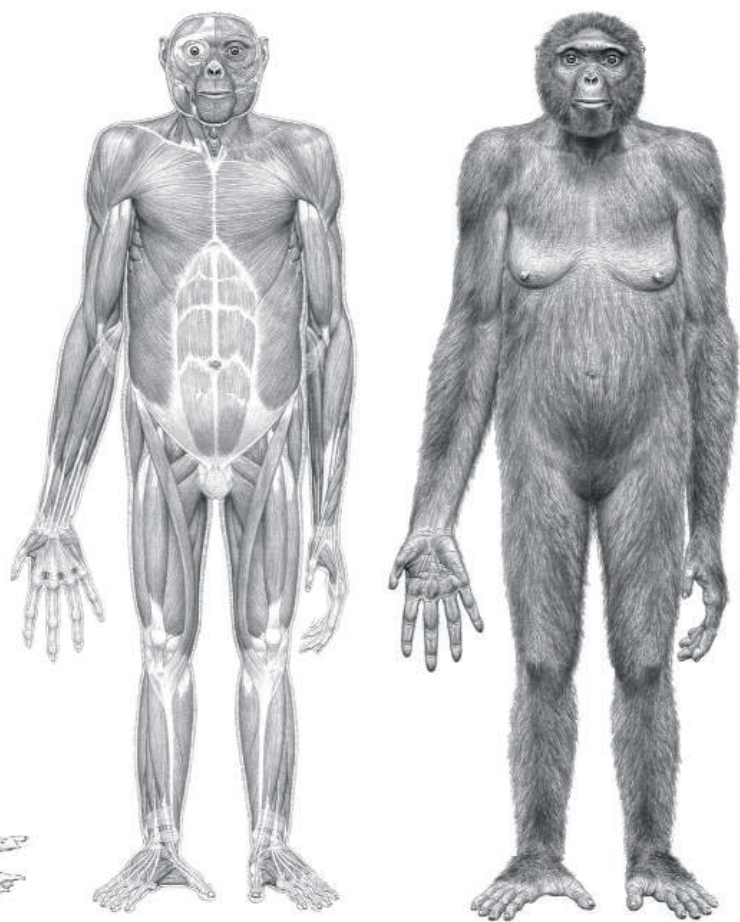

From the inside out. Artist's reconstructions show how Ardi's skeleton, muscles, and body looked and how she would have moved on top of branches. 
ered a hallmark of hominins. "We thought Lucy was the find of the century but, in retrospect, it isn't," says paleoanthropologist Andrew Hill of Yale University. "It's worth the wait."

To some researchers' surprise, the female skeleton doesn't look much like a chimpanzee, gorilla, or any of our closest living primate relatives. Even though this species probably lived soon after the dawn of humankind, it was not transitional between African apes and humans. "We have seen the ancestor, and it is not a chimpanzee," says paleoanthropologist Tim White of the University of California, Berkeley, co-director of the Middle Awash research group, which discovered and analyzed the fossils.

Instead, the skeleton and pieces of at least 35 additional individuals of $\mathrm{Ar}$. ramidus reveal a new type of early hominin that was neither chimpanzee nor human. Although the team suspects that Ar. ramidus may have given rise to Lucy's genus, Australopithecus, the fossils "show for the first time that there is some new evolutionary grade of hominid that is not Australopithecus, that is not Homo," says paleontologist Michel Brunet of the College de France in Paris.

In 11 papers published in this issue and online, the team of 47 researchers describes how Ar. ramidus looked and moved. The skeleton, nicknamed "Ardi," is from a female who lived in a woodland (see sidebar, p. 40), stood about 120 centimeters tall, and weighed about 50 kilograms. She was thus as big as a chimpanzee and had a brain size to match. But she did not knuckle-walk or swing through the trees like living apes. Instead, she walked upright, planting her 岑 feet flat on the ground, perhaps eating nuts, insects, and small mammals in the woods.

She was a "facultative" biped, say the authors, still living in both worlds - upright on the ground but also able to move on all fours on top of branches in the trees, with an opposable big toe to grasp limbs. "These things were very odd creatures," says paleoanthropologist Alan Walker of Pennsylvania State University, University Park. "You know what Tim [White] once said: If you wanted to find something that moved like these things, you'd have to go to the bar in Star Wars."

Most researchers, who have waited 15 years for the publication of this find, agree that Ardi is indeed an early hominin. They praise the detailed reconstructions needed to piece together the crushed bones.

"This is an extraordinarily impressive work of reconstruction and description, well worth waiting for," says paleoanthropologist David Pilbeam of Harvard University. "They did this job very, very well," agrees neurobiologist Christoph Zollikofer of the University of Zurich in Switzerland.

But not everyone agrees with the team's interpretations about how Ar. ramidus walked upright and what it reveals about our ancestors.
"The authors ... are framing the debate that will inevitably follow," because the description and interpretation of the finds are entwined, says Pilbeam. "My first reaction is to be skeptical about some of the conclusions," including that human ancestors never went through a chimpanzee-like phase. Other researchers are focusing intently on the lower skeleton, where some of the anatomy is so primitive that they are beginning to argue over just what it means to be "bipedal." The pelvis, for example, offers only "circumstantial" evidence for upright walking, says Walker. But however the debate about Ardi's locomotion and identity evolves, she provides the first hard evidence

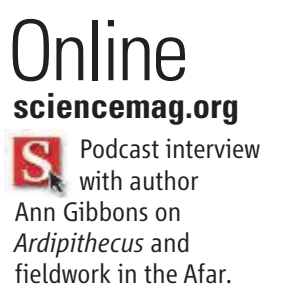

fieldwork in the Afar.

knew it was a hominin molar. Over the next few days, the team scoured the area on hands and knees, as they do whenever an important piece of hominin is found (see story, p. 41), and collected the lower jaw of a child with the milk molar still attached. The molar was so primitive that the team knew they had found a hominin both older and more primitive than Lucy. Yet the jaw also had derived traits - novel evolutionary characters - shared with Lucy's species, Au. afarensis, such as an upper canine shaped like a diamond in side view.

The team reported 15 years ago in Nature that the fragmentary fossils belonged to the "long-sought potential root species for the Hominidae." (They first called it Au. ramidus, then, after finding parts of the skeleton, changed it to Ar. ramidus - for the Afar words for "root" and "ground.") In response to comments that he needed leg bones to prove Ar. ramidus was an upright hominin, White joked that he would be delighted with more parts, specifically a thigh and an intact skull, as though placing an order.

Within 2 months, the team delivered. In November 1994, as the fossil hunters crawled up an embankment, Berkeley graduate student Yohannes Haile-Selassie of Ethiopia, now a paleoanthropologist at the Cleveland Museum of Natural History in Ohio, spotted two pieces of a bone from the palm of a hand. That was soon followed by pieces of a pelvis; leg, ankle, and foot bones; many of the bones of the hand and arm; a lower jaw with teeth — and a cranium. By January 1995, it was apparent that they had made the rarest of rare finds, a partial skeleton.
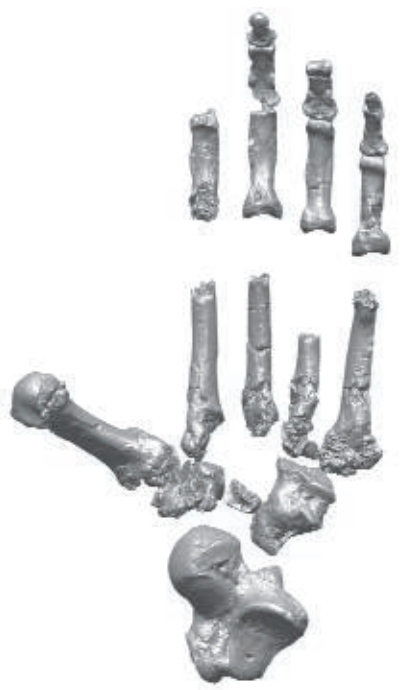
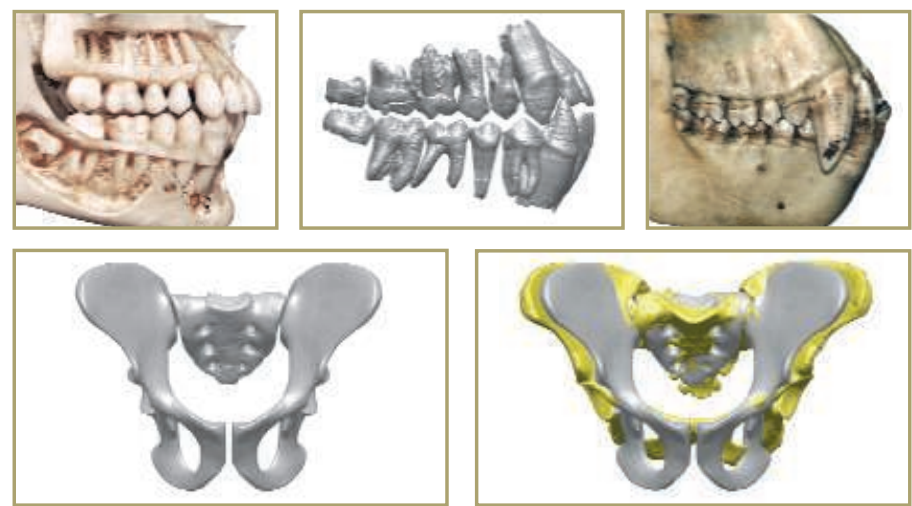

Unexpected anatomy. Ardi has an opposable toe (left) and flexible hand (right); her canines (top center) are sized between those of a human (top left) and chimp (top right); and the blades of her pelvis (lower left) are broad like Lucy's (yellow).

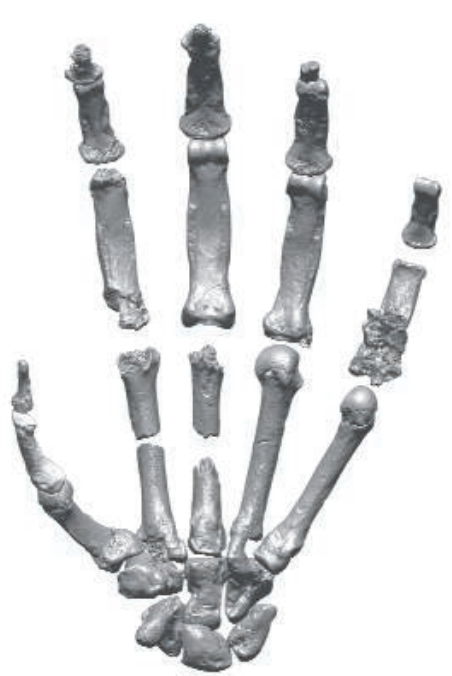


FOSSILS OF THE HUMAN FAMILY

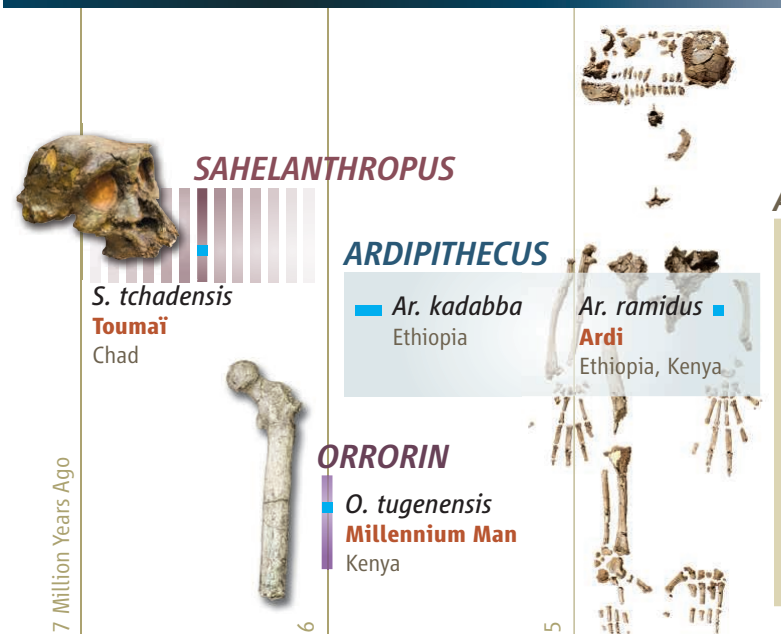

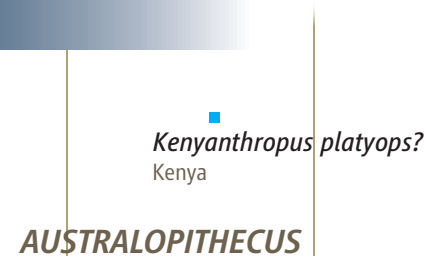

AUSTRALOPITHECUS

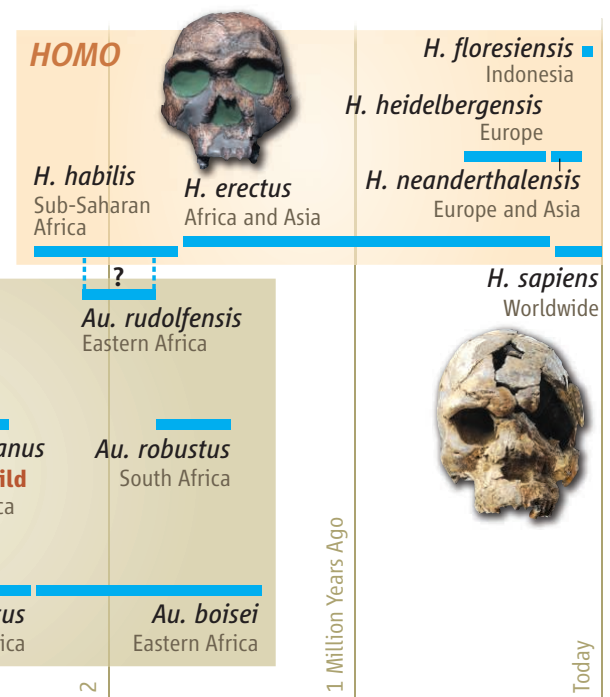

Pleistocene Epoch

Holocene Epoch

Miocene Epoch

Pliocene Epoch

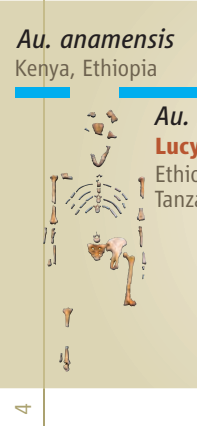

Au.

Taung Child South Africa

Au. bahrelghazali?

Au. bahrelghazali?

Abel

Au. aethiopicus
Eastern Africa

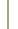

Filling a gap. Ardipithecus provides a link between earlier and later hominins, as seen in this timeline showing important hominin fossils and taxa.

It is one of only a half-dozen such skeletons known from more than 1 million years ago, and the only published one older than Lucy.

It was the find of a lifetime. But the team's excitement was tempered by the skeleton's terrible condition. The bones literally crumbled when touched. White called it road kill. And parts of the skeleton had been trampled and scattered into more than 100 fragments; the skull was crushed to 4 centimeters in height. The researchers decided to remove entire blocks of sediment, covering the blocks in plaster and moving them to the National Museum of Ethiopia in Addis Ababa to finish excavating the fossils.

It took three field seasons to uncover and extract the skeleton, repeatedly crawling the site to gather $100 \%$ of the fossils present. At last count, the team had cataloged more than 110 specimens of Ar. ramidus, not to mention 150,000 specimens of fossil plants and animals. "This team seems to suck fossils out of the earth," says anatomist C. Owen Lovejoy of Kent State University in Ohio, who analyzed the postcranial bones but didn't work in the field. In the lab, he gently

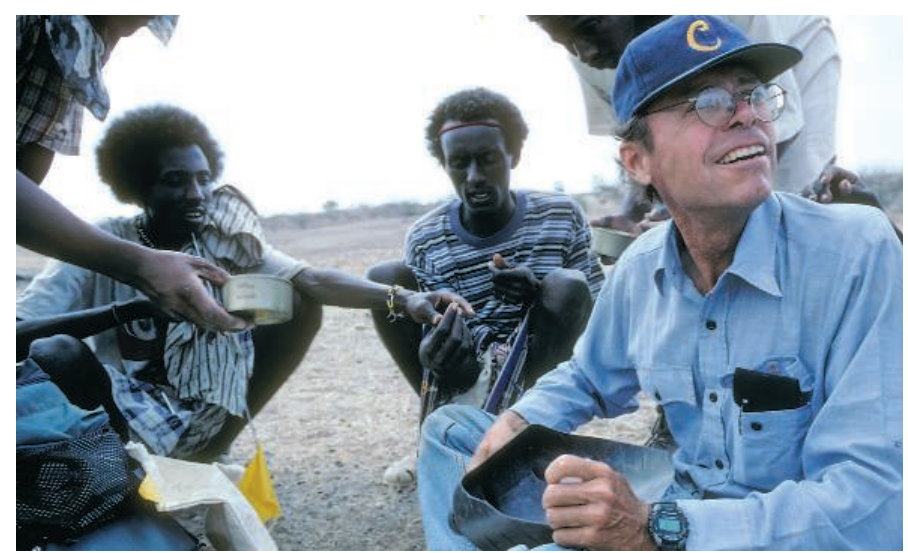

Fossil finders. Tim White and local Afar fossil hunters pool their finds after scouring the hillside at Aramis. on the task. "You go piece by piece."

Once he had reassembled the pieces in a digital reconstruction, he and paleoanthropologist Berhane Asfaw of the Rift Valley Research Service in Addis Ababa compared the skull with those of ancient and living primates in museums worldwide. By March of this year, Suwa was satisfied with his 10 th reconstruction. Meanwhile in Ohio, Lovejoy made physical models of the pelvic pieces based on the original fossil and the CT scans, working closely with Suwa. He is also satisfied that the 14 th version of the pelvis is accurate. "There was an Ardipithecus that looked just like that," he says, holding up the final model in his lab.

\section{Putting their heads together}

As they examined Ardi's skull, Suwa and Asfaw noted a number of characteristics. Her lower face had a muzzle that juts out less than a chimpanzee's. The cranial base is short from front to back, indicating that her head balanced atop the spine as in later upright walkers, rather than to the front of the spine, as in quadrupedal apes. Her face is in a more vertical position than in unveils a cast of a tiny, pea-sized sesamoid bone for effect. "Their obsessiveness gives you-this!"

White himself spent years removing the silty clay from the fragile fossils at the National Museum in Addis Ababa, using brushes, syringes, and dental tools, usually under a microscope. Museum technician Alemu Ademassu made a precise cast of each piece, and the team assembled them into a skeleton.

Meanwhile in Tokyo and Ohio, Suwa and Lovejoy made virtual reconstructions of the crushed skull and pelvis. Certain fossils were taken briefly to Tokyo and scanned with a custom micro-computed tomography (CT) scanner that could reveal what was hidden inside the bones and teeth. Suwa spent 9 years mastering the technology to reassemble the fragments of the cranium into a virtual skull. "I used 65 pieces of the cranium," says Suwa, who estimates he spent 1000 hours chimpanzees. And her teeth, like those of all later hominins, lack the daggerlike sharpened upper canines seen in chimpanzees. The team realized that this combination of traits matches those of an even older skull, 6-million to 7-million-year-old Sahelanthropus tchadensis, found by Brunet's team in Chad. They conclude that both represent an early stage of human evolution, distinct from both Australopithecus and chimpanzees. "Similarities with Sahelanthropus are striking, in that it also represents a first-grade hominid," agrees Zollikofer, who did a three-dimensional reconstruction of that skull.

Another, earlier species of Ardipithecus-Ar. kadabba, dated from 5.5 million to 5.8 million years ago but known only from teeth and bits and pieces of skeletal bones - is part of that grade, too. And Ar. kadabba's canines and other teeth seem to match those of a third very ancient specimen, 6-million-year-old Orrorin tugenensis from 


\section{Ardipithecus ramidus NEWSFOCUS}

Kenya, which also has a thighbone that appears to have been used for upright walking (Science, 21 March 2008, p. 1599). So, "this raises the intriguing possibility that we're looking at the same genus" for specimens now put in three genera, says Pilbeam. But the discoverers of $O$. tuge-

nensis aren't so sure. "As for Ardi and Orrorin being the same genus, no, I don't think this is possible, unless one really wants to accept an unusual amount of variability" within a taxon, says geologist Martin Pickford of the College de France, who found Orrorin with Brigitte Senut of the National Museum of Natural History in Paris.

Whatever the taxonomy of Ardipithecus and the other very ancient hominins, they represent "an enormous jump to Australopithecus," the next hominin in line (see timeline, p. 38), says australopithecine expert William Kimbel of Arizona State University, Tempe. For example, although Lucy's brain is only a little larger than that of Ardipithecus, Lucy's species, $A u$. afarensis, was an adept biped. It walked upright like humans, venturing increasingly into more diverse habitats, including grassy savannas. And it had lost its opposable big toe, as seen in 3.7-million-year-old footprints at Laetoli, Tanzania, reflecting an irreversible commitment to life on the ground.

Lucy's direct ancestor is widely considered to be Au. anamensis, a hominin whose skeleton is poorly known, although its shinbone suggests it walked upright 3.9 million to 4.2 million years ago in Kenya and Ethiopia. Ardipithecus is the current leading candidate for $A u$. anamensis's ancestor, if only because it's the only putative hominin in evidence between 5.8 million and 4.4 million years ago. Indeed, $A u$. anamensis fossils appear in the Middle Awash region just 200,000 years after Ardi.

\section{Making strides}

But the team is not connecting the dots between $\mathrm{Au}$. anamensis and Ar. ramidus just yet, awaiting more fossils. For now they are focusing on the anatomy of Ardi and how she moved through the world. Her foot is primitive, with an opposable big toe like that used by living apes to grasp branches. But the bases of the four other toe bones were oriented so that they reinforced the forefoot into a more rigid lever as she pushed off. In contrast, the toes of a chimpanzee curve as flexibly as those in their hands, say Lovejoy and co-author Bruce Latimer of Case Western Reserve University in Cleveland. Ar. ramidus "developed a pretty good bipedal foot while at the same time keeping an opposable first toe," says Lovejoy.

The upper blades of Ardi's pelvis are shorter and broader than in apes. They would have lowered the trunk's center of mass, so she could balance on one leg at a time while walking, says Lovejoy. He also infers from the pelvis that her spine was long and curved like a human's rather than short and stiff like a chimpanzee's. These changes suggest to him that $A r$ r ramidus "has been bipedal for a very long time."

Yet the lower pelvis is still quite large and primitive, similar to African apes rather than hominins. Taken with the opposable big toe, and primitive traits in the hand and foot, this indicates that Ar. ramidus didn't walk like Lucy and was still spending a lot of time in the trees. But it wasn't suspending its body beneath branches like African apes or climbing vertically, says Lovejoy. Instead, it was a slow, careful
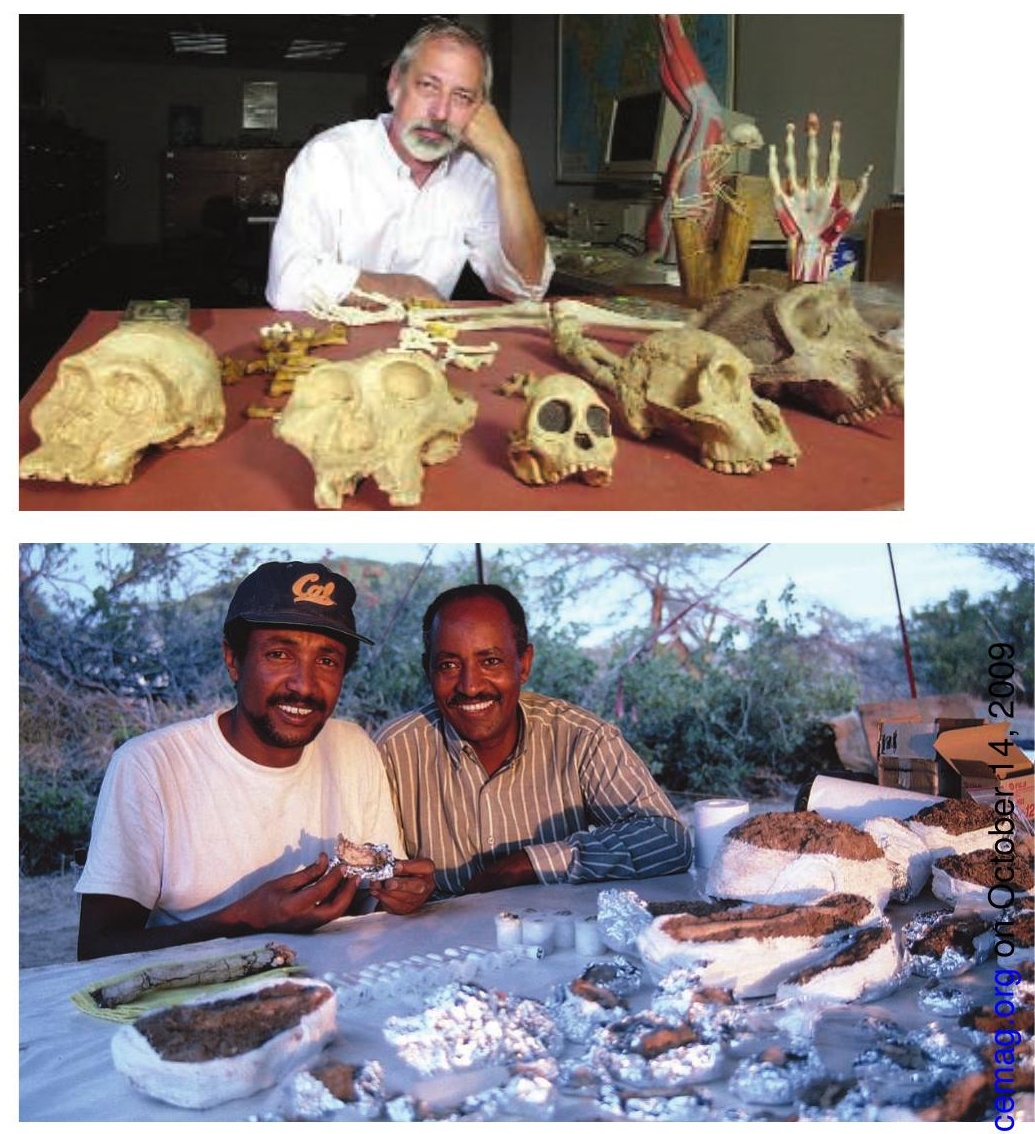

Dream team. Gen Suwa (left) in Tokyo focused on the skull; C. Owen Lovejoy (top right) in Kent, Ohio, studied postcranial bones; and Yohannes Haile-Selassie and Berhane Asfaw found and analyzed key fossils in Ethiopia.

climber that probably moved on flat hands and feet on top of branches in the midcanopy, a type of locomotion known as palmigrady. For example, four bones in the wrist of Ar. ramidus gave it a more flexible hand that could be bent backward at the wrist. This is in contrast to the hands of knuckle-walking chimpanzees and gorillas, which have stiff wrists that absorb forces on their knuckles.

However, several researchers aren't so sure about these inferences. Some are skeptical that the crushed pelvis really shows the anatomical details needed to demonstrate bipedality. The pelvis is "suggestive" of bipedality but not conclusive, says paleoanthropologist Carol Ward of the University of Missouri, Columbia. Also, Ar. ramidus "does not appear to have had its knee placed over the ankle, which means that when walking bipedally, it would have had to shift its weight to the side," she says. Paleoanthropologist William Jungers of Stony Brook University in New York state is also not sure that the skeleton was bipedal. "Believe me, it's a unique form of bipedalism," he says. "The postcranium alone would not unequivocally signal hominin status, in my opinion." Paleoanthropologist Bernard Wood of George Washington University in Washington, D.C., agrees. Looking at the skeleton as a whole, he says, "I think the head is consistent with it being a hominin, ... but the rest of the body is much more questionable."

All this underscores how difficult it may be to recognize and define bipedality in the earliest hominins as they began to shift from trees to ground. One thing does seem clear, though: The absence of many specialized traits found in African apes suggests that our ancestors never knuckle-walked.

That throws a monkey wrench into a hypothesis about the last common ancestor of living apes and humans. Ever since Darwin 


\section{Habitat for Humanity}

ARAMIS, ETHIOPIA-A long cairn of black stones marks the spot where a skeleton of Ardipithecus ramidus was found, its bones broken and scattered on a barren hillside. Erected as a monument to an ancient ancestor in the style of an Afar tribesman's grave, the cairn is a solitary marker in an almost sterile zone, devoid of life except for a few spindly acacia trees and piles of sifted sediment.

That's because the Middle Awash research team sucked up everything in sight at this spot, hunting for every bit of fossil bone as well as clues to the landscape 4.4 million years ago, when Ardipithecus died here. "Literally, we crawled every square inch of this locality," recalls team co-leader Tim White of the University of California, Berkeley. "You crawl on your hands and knees, collecting every piece of bone, every piece of wood, every seed, every snail, every scrap. It was $100 \%$ collection." The heaps of sediment are all that's left behind from that fossil-mining operation, which yielded one of the most important fossils in human evolution (see main text, p. 36), as well as thousands of clues to its ecology and environment.

The team collected more than 150,000 specimens of fossilized plants and animals from nearby localities of the same age, from elephants to songbirds to millipedes, including fossilized wood, pollen, snails, and larvae. "We have crates of bone splinters," says White.

A team of interdisciplinary researchers then used these fossils and thousands of geological and isotopic samples to reconstruct Ar. ramidus's Pliocene world, as described in companion papers in this issue (see p. 66 and 87). From these specimens, they conclude that Ardi lived in a woodland, climbing among hackberry, fig, and palm trees and coexisting with monkeys, kudu antelopes, and peafowl. Doves and parrots flew overhead. All these creatures prefer woodlands, not the open, grassy terrain often conjured for our ancestors.

The team suggests that $A r$. ramidus was "more omnivorous" than chimpanzees, based on the size, shape, and enamel distribution of its teeth. It probably supplemented woodland plants such as fruits, nuts, and tubers with the occasional insects, small mammals, or bird eggs. Carbon-isotope studies of teeth from five individuals show that Ar. ramidus ate mostly woodland, rather than grassland, plants. Although Ar. ramidus probably ate

suggested in 1871 that our ancestors arose in Africa, researchers have debated whether our forebears passed through a great-ape stage in which they looked like proto-chimpanzees (Science, 21 November 1969 , p. 953). This "troglodytian" model for early human behavior (named for the common chimpanzee, Pan troglodytes) suggests that the last common ancestor of the African apes and humans once had short backs, arms adapted for swinging, and a pelvis and limbs adapted for knuckle walking. Then our ancestors lost these traits, while chimpanzees and gorillas kept them. But this view has been uninformed by fossil evidence because there are almost no fossils of early chimpanzees and gorillas.

Some researchers have thought that the ancient African ape bauplan was more primitive, lately citing clues from fragmentary fossils of apes that lived from 8 million to 18 million years ago. "There's been growing evidence from the Miocene apes that the common ancestor may have been more primitive," says Ward. Now Ar. ramidus strongly supports that notion. The authors repeatedly
Past and present. Ardipithecus's woodland was more like Kenya's Kibwezi Forest (left) than Aramis today.

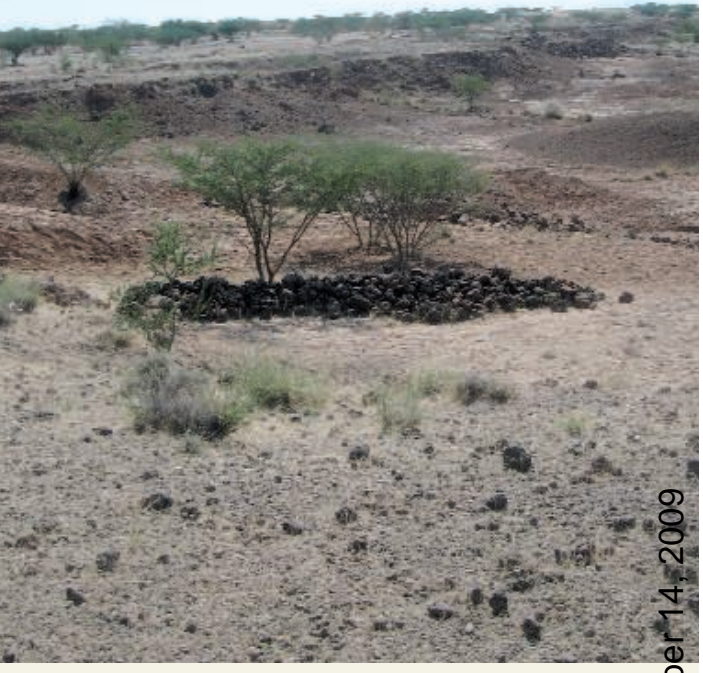

figs and other fruit when ripe, it didn't consume as much fruit as chimpanzees do today.

This new evidence overwhelmingly refutes the once-favored but now moribund hypothesis that upright-walking hominins arose in open grasslands. "There's so much good data here that people aren't going to be able to question whether early hominins were living in woodlands," says paleoanthropologist Andrew Hill of Yale University. "Savannas had nothing to do with upright walking."

Geological studies indicate that most of the fossils were buried within a relatively short window of time, a few thousand to, at most, 100,000 years ago, says geologist and team co-leader Giday WoldeGabriel of the Los Alamos National Laboratory in New Mexico. During that sliver of time, Aramis was not a dense tropical rainforest with a thick canopy but a humid, cooler woodland. The best modern analog is the Kibwezi Forest in Kenya, kept wet by groundwater, according to isotope expert Stanley Ambrose of the University of Illinois, Urbana-Champaign. These woods have open stands of trees, some 20 meters high, that let the sun reach shrubs and grasses on the ground.

Judging from the remains of at least 36 Ardipithecus individuals found so far at Aramis, this was prime feeding ground for a generalized early biped. "It was the habitat they preferred," says White.

-A.G.

note the many ways that Ar. ramidus differs from chimpanzees and gorillas, bolstering the argument that it was those apes that changed the most from the primitive form.

But the problem with a more "generalized model" of an arboreal ape is that "it is easier to say what it wasn't than what it was," says Ward. And if the last common ancestor, which according to genetic studies lived 5 million to 7 million years ago, didn't look like a chimp, then chimpanzees and gorillas evolved their numerous similarities independently, after gorillas diverged from the chimp/human line. "I find [that] hard to believe," says Pilbeam.

As debate over the implications of Ar. ramidus begins, the one thing that all can agree on is that the new papers provide a wealth of data to frame the issues for years. "No matter what side of the arguments you come down on, it's going to be food for thought for generations of graduate students," says Jungers. Or, as Walker says: "It would have been very boring if it had looked half-chimp.'

-ANN GIBBONS 